\title{
Electrocardiographic abnormalities and some laboratory findings in patients with subarachnoid haemorrhage
}

\author{
A. Eisalo, J. Peräsalo, and P. I. Halonen \\ From First Department of Medicine, University Central Hospital, Helsinki 29, Finland
}

The electrocardiogram and the urinary excretion of catecholamines and metanephrines, plasma corticosteroids, blood sugar, NEFA, serum cholesterol, serum triglycerides, SGOT, SGPT, $S L D H, S C P K$, serume lectrolytes, and serum lactic acid have been measured in 20 patients with

- subarachnoid haemorrhage, including 6 patients with earlier known arterial hypertension, from their admission to the hospital up to their discharge or death.

Electrocardiographic abnormalities were seen in all patients during the follow-up time. Electrocardiographic changes appeared most often at admission or on the first hospital day. An abnormal $U$ wave was the change more often seen ( 13 patients). Next in frequency was $Q T$ interval prolongation (II patients), and ST depression was seen in Io patients. SVI $+R V_{5}$ exceeded - $35 \mathrm{~mm}$ in 8 patients. The other abnormalities were $T$ wave flattening and/or inversion, large $P$ wave, $S T$ elevation, prolonged $P Q$ interval, atrial fibrillation, sinus bradycardia and tachycardia, and ventricular extrasystoles.

Twelve patients survived the disease: in 8 of them the electrocardiogram returned to normal during the follow-up. The persisting abnormalities in electrocardiograms of the 4 other survivors were abnormal $U$ wave in 3 patients, large $P$ wave in $2, S T$ elevation in $I, S T$ depression in $I$, sinus bradycardia in $I$, and sinus tachycardia in $I$.

- No clear, uniform correlation could be found between any single laboratory finding and electrocardiographic abnormalities.

Since Byer, Ashman, and Toth (1947) reported large upright $T$ waves and $Q T$ interval prolongation in the electrocardiogram of a patient with subarachnoid haemorrhage, many papers have been published reporting various - changes !in the electrocardiograms of patients with subarachnoid haemorrhage (Hersch, 1964; Koskelo, Punsar, and Sipilä, 1964; Srivastava and Robson, 1964; Hoffbrand and

- Morgan, 1965; Ilinskii and Astrakhantseva, 1967; Hunt, McRae, and Zapf, 1969; Kreus,

- Kemilä, and Takala, 1969; Wong and Cooper, 1969).

The purpose of the present study was to find out the relation between the abnormalities in the electrocardiogram and certain clinical laboratory data.

\section{Subjects and methods}

[wenty patients with subarachnoid haemorrhage sere studied. The diagnosis was based on the finical symptoms and blood-stained cerebro-

Received 22 March 197 I. spinal fluid at admission. There were 9 women (age range 39-7I years) and II men (2I-7I years). Eighteen of the patients were seen at hospital within 12 hours of the first symptoms. For the other 2 patients the time intervals from the first subjective symptoms to admission were 17 and 24 hours (Cases 20 and 5, respectively). Seven patients were unconscious on admission (Table I). Eight of the patients died during their hospital stay (Table $I$ ).

In 6 patients, hypertension (over 160/100 $\mathrm{mmHg}$ ) was known to have been present for years (Table I). Only one patient had at admission high voltage electrocardiographic abnormalities reflecting left ventricular hypertrophy. Not one of these hypertensive patients had congestive heart failure.

A 12-lead electrocardiogram was registered in all patients within 2 hours of admission. In 13 patients an electrocardiogram was registered both before and after lumbar puncture at admission. Subsequent electrocardiograms were recorded on the first and third mornings in hospital and then every 2 to 3 days up to 3 weeks; thereafter it was taken once a week up to the patient's discharge from hospital. 
TABLE I Appearance and duration of electrocardiographic changes in 20 patients with subarachnoid haemorrhage

\begin{tabular}{|c|c|c|c|c|c|c|c|c|c|}
\hline $\begin{array}{l}\text { Patient } \\
\text { No. }\end{array}$ & $\begin{array}{l}\text { Age } \\
(y r)\end{array}$ & Sex & $\begin{array}{l}\text { Abnormal } U \\
\text { wave }\end{array}$ & $\begin{array}{l}Q T \text { prolongation } \\
(\% \text { of normal) }\end{array}$ & $\begin{array}{l}T \text { wave inver- } \\
\text { sion and } \\
\text { flattening }\end{array}$ & $\begin{array}{l}S T \\
\text { depression }\end{array}$ & $\begin{array}{l}S T \\
\text { elevation }\end{array}$ & $\begin{array}{l}P \text { wave } \\
\geqq 2.5 \mathrm{~mm}\end{array}$ & $\begin{array}{l}S V I+R V \\
>35 \mathrm{~mm}\end{array}$ \\
\hline
\end{tabular}

\begin{tabular}{ll}
\hline 1 & 21 \\
$2 \star$ & 65 \\
3 & 46 \\
4 & 60 \\
7 & 69 \\
8 & 28 \\
10 & 71 \\
11 & 61 \\
$13^{\star}$ & 59 \\
14 & 57 \\
$15^{\star}$ & 37 \\
$18^{\star}$ & 71 \\
$19^{\star}$ & 52 \\
$20^{\star}$ & 48
\end{tabular}

$\begin{array}{ll}M & \text { A } \\ M & \\ M & \text { V } \\ \text { F } & \text { V } \\ \text { F } & \text { I-XI } \\ \text { M } & \text { P } \\ \text { F } & \text { A-I } \\ \text { F } & \text { A- } \\ \text { M } & \\ \text { M } & \\ \text { M } & \\ \text { F } & \text { A } \\ \text { M } & \text { A }\end{array}$

A-XII

$\mathrm{V}-\mathrm{XI}$ (neg.)

$\mathrm{V}-\mathrm{XI}$

I-XIII (neg.)

PL-

A-

-

Patients with known hypertension

\begin{tabular}{rr}
5 & 61 \\
6 & 39 \\
9 & 61 \\
12 & 56 \\
16 & 56 \\
$17^{\star}$ & 60 \\
\hline
\end{tabular}

$\begin{array}{ll}\text { F } & \text { A-XI } \\ \text { F } & \text { A-(neg.) } \\ \text { M } & \\ \text { M } & \\ \text { F } & \text { A-III } \\ \text { F } & \text { A-(neg.) } \\ & \text { 13 } \\ & 65\end{array}$

A

A-III $(25 \%)$

III-XI

A-III

$\mathrm{XI}$

VI-VIII

A-III $(25 \%)$

I

II $(20 \%)$

A

A- $(27 \%)$

A $(20 \%)$

A- $(20 \%)$

VI
III
PL-
I
A-
A, I
A-
A-
VI
I-III
V-

A-

XVIII-

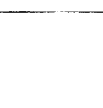

A-X

ڤ

Total

$\%$ of total

65

A-XIV

A-

$\begin{array}{ll} & \text { IX } \\ \text { III-V } & \text { I-III } \\ \text { VII- } & \text { A- }\end{array}$

A-VI

($$
\text { V- }
$$

A-
I-
PL-

A-
I-
PL-

A-III

A- $(25 \%)$

III

A-

VII

II

$\mathrm{A}=$ admission time before lumbar puncture; $\mathrm{PL}=$ postlumbar puncture at admission; I, II, III, etc. $=$ hospital days after admission.

Patient No. 6 was referred to surgery on tenth hospital day.

$\star$ Unconscious on admission.

\section{Electrocardiographic criteria}

The criteria of Lipman and Massie (1965) were used. A pulse rate exceeding roo a minute was regarded as tachycardia and one under 60 a minute as bradycardia. The $\mathbf{P}$ wave was measured in lead II and was considered to be abnormal if it exceeded $2.5 \mathrm{~mm}$. When the $U$ wave was more than I $\mathrm{mm}$ in height it was held to be abnormal. SVI + $\mathrm{RV}_{5}$ was regarded as normal when it was below $35 \mathrm{~mm}$. ST elevation of $2.5 \mathrm{~mm}$ or more was regarded as pathological, and a depression of the ST segment of I mm or more was abnormal. The QT interval was matched for sex and pulse rate (Lipman and Massie, 1965). In cases of TU fusion, the apex of the $T$ wave (aT) was used as the reference point (Lepeschkin, 1955).

Laboratory tests were performed at admission or on the first hospital morning and thereafter every 2 days for 2 weeks, and then once a week as follows. Blood sugar (normal range $60-90 \mathrm{mg}$ / $100 \mathrm{ml}$ ), serum potassium, sodium and chloride (respective normal ranges $3.6-5.5 \mathrm{mM} / 1$., 135-148 $\mathrm{mM} / 1$. and 99-I I I $\mathrm{mM} / 1$.), serum non-esterified fatty acids (NEFA) (normal range $0.5-0.95 \mathrm{mEq} /$ 1.), plasma corticosteroids (normal range IO-3I $\mathrm{mg} / \mathrm{I00} \mathrm{ml}$ ), serum lactic dehydrogenase (SLDH) (normal values <I80 IU), serum aspartate aminotransferase (SGOT) (normal values $<20$ IU), serum alanine aminotransferase (SGPT) (normal values < $19 \mathrm{IU}$ ), serum creatine phosphokinase (CPK) (normal values $<\mathrm{I} \cdot 5 \mathrm{U} / \mathrm{ml}$ ), serum cholesterol (normal range $170-280 \mathrm{mg} / \mathrm{I} 00 \mathrm{ml}$ ), serum triglycerides (normal range $0 \cdot 4-1 \cdot 7 \mathrm{mM} / 1$ ), and blood lactic acid (normal range 6-16 mg/roo $\mathrm{ml}$ ). The urinary excretion of catecholamines and metanephrines was determined, if possible during the first 6 hours after admission; thereafter 24hour urine collections were made on the first hospital day and then every 2 to 3 days for 2 weeks. In our laboratory the normal value for total excretion of adrenaline and noradrenaline is $<100 \mu \mathrm{g} / 24 \mathrm{hr}$; the amount of adrenaline normally being under 25 per cent of the total excretion. The normal range for metanephrine excretion is $0.3-0.9 \mathrm{mg} / 24$ hours.

To avoid the influence of incomplete urine sampling the values for catecholamine and metanephrine outputs are given in $\mu \mathrm{g} / \mathrm{mg}$ of creatinine.

\section{Results}

Electrocardiographic abnormalities These were seen in all of our 20 patients during the follow-up time. These abnormalities and their appearance and duration are listed in Table I. At the time of admission, abnormalities were seen in the cardiograms of 18 patients (Table $\mathbf{r}$ ). 


\begin{tabular}{|c|c|c|c|c|c|c|}
\hline Bradycardia & Tachycardia & $\begin{array}{l}\text { Atrial } \\
\text { fibrillation }\end{array}$ & $\begin{array}{l}\text { Ventricular } \\
\text { extrasystoles }\end{array}$ & $\begin{array}{l}\text { ECG normal } \\
\text { on day }\end{array}$ & $\begin{array}{l}\text { Time of death after } \\
\text { admission (patient } \\
\text { died hours or days } \\
\text { after admission) }\end{array}$ & $T$ flattening \\
\hline II-XV & & & XII & $\begin{array}{l}\text { XVII } \\
\text { XV } \\
\text { XVI } \\
\text { XIV }\end{array}$ & & \\
\hline WIII & & & & $\mathrm{XV}$ & & \\
\hline & & & & IX & & $\mathrm{r}$ \\
\hline A & $\begin{array}{l}\text { A- } \\
\text { I- } \\
\text { XXVIII- }\end{array}$ & A- & PL & & $\begin{array}{c}3 \frac{1}{2} \mathrm{hr} \\
21 \mathrm{dy} \\
5 \frac{1}{2} \mathrm{hr} \\
27 \frac{1}{2} \mathrm{hr} \\
6 \mathrm{dy} \\
35 \mathrm{dy}\end{array}$ & \\
\hline $\begin{array}{l}\text { XIV } \\
\text { A, III }\end{array}$ & & & & XVI & & \\
\hline IV-XVI & $\begin{array}{l}\text { III- } \\
\text { III- }\end{array}$ & V- & & XIX & $\begin{array}{r}\text { I0 dy } \\
5 \mathrm{hr}\end{array}$ & A- \\
\hline $\begin{array}{r}7 \\
35\end{array}$ & $\begin{array}{r}5 \\
25\end{array}$ & $\begin{array}{r}2 \\
10\end{array}$ & $\begin{array}{r}2 \\
10\end{array}$ & $\begin{array}{r}8 \\
40\end{array}$ & & \\
\hline
\end{tabular}

An abnormal $U$ wave was the change most often seen (in 13 patients). At admission it was present in the electrocardiogram of 9 patients, 7 of whom had at the same time raised blood pressure (over $160 / 90 \mathrm{mmHg}$ ). There were 5 other patients with raised blood pressure but without an abnormal $U$ wave. The $U$ wave was negative in 4 patients (Table ' $I)$. The abnormal $U$ wave persisted in 2 patients (Table I).

$Q T$ interval prolongation was the abnormality - next in frequency (I I patients), and was the most common one seen at admission (IO - patients); with one exception it was not present in any of the cases after the 3rd hospital day.

$S T$ elevation was seen in 5 patients. This abnormality did not disappear in any case (Table I): 4 of these patients died.

$S T$ depression was seen in ro patients (Table ז), in 6 of whom it disappeared. Six patients with ST depression died.

$T$ wave flattening and/or inversion occurred in 9 patients (Table $\mathrm{I}$ ). Transient $\mathrm{T}$ wave flat- tening without subsequent $T$ inversion was present in 2 patients. Inversion of the $T$ wave preceded by flattening was seen in 6 patients. $T$ wave inversion only was seen in one case.

$A$ prominent $P$ wave could be seen in the electrocardiogram of 7 patients (Table $\mathrm{I}$ ). This change persisted in 2 patients throughout the follow-up time.

$A$ prolonged $P Q$ interval was measured in only one patient (Case 2). It was $0.24 \mathrm{sec}$ at admission and normal on the 3rd day. SVI + $\mathrm{RV}_{5}=35 \mathrm{~mm}$ occurred in 8 patients. Of 6 patients who were known to have had hypertension earlier this was seen in only 3 (Table I).

Sinus bradycardia occurred in 7 patients (Table I), the pulse rate range being 50-58/ min.

Five patients had sinus tachycardia, the pulse rate range being $103-132 / \mathrm{min}$.

Transient ventricular extrasystoles were registered in 2 patients. In the one they appeared 

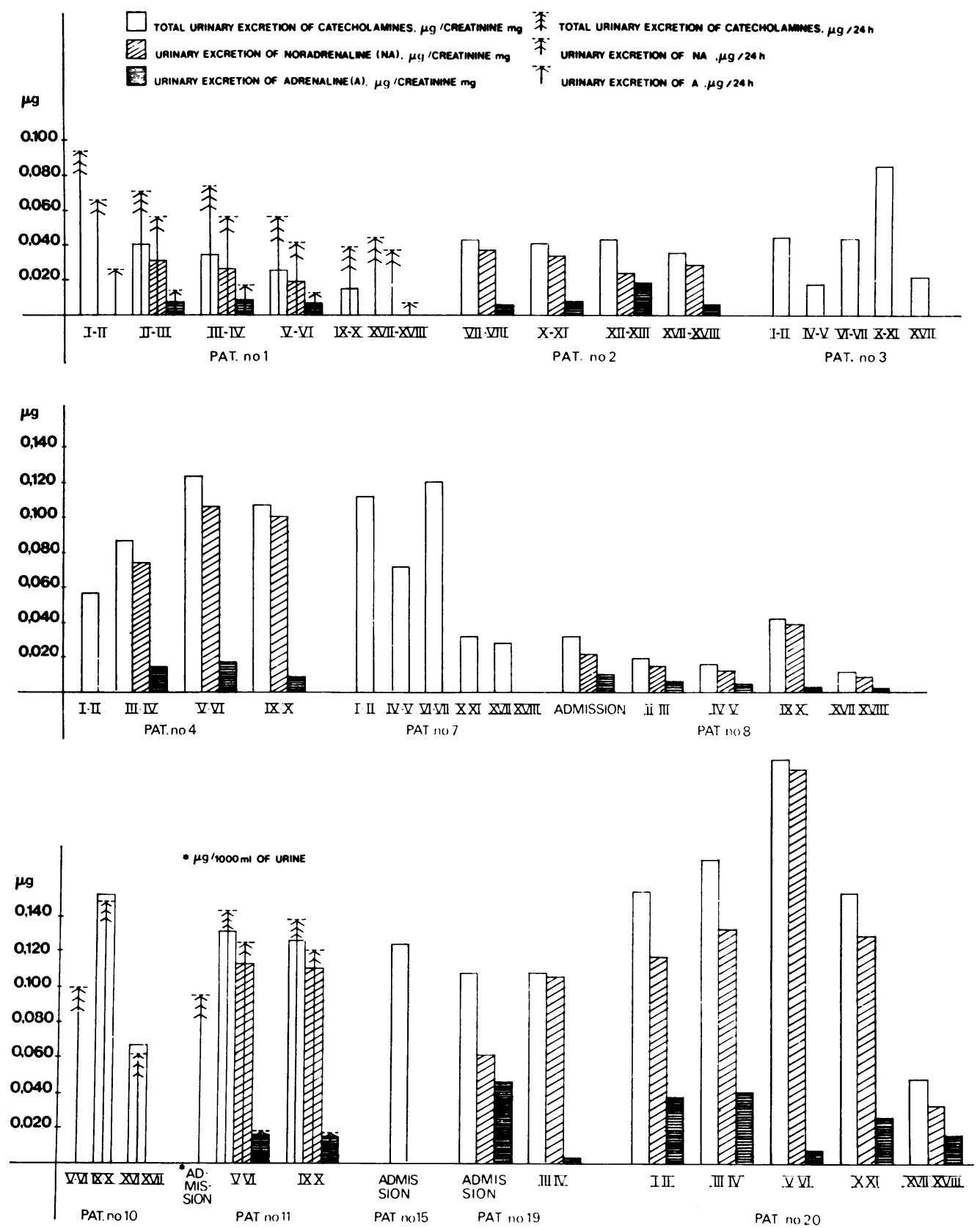

FIG. Ia The total urinary excretion of catecholamines, noradrenaline, and adrenaline in patients with subarachnoid haemorrhage with no earlier known arterial hypertension. I, II, III etc. stand for hospital days after admission.

after the lumbar puncture done at admission (Table 2), and in the other there was a concomitant relative rise in the urinary excretion of adrenaline.

Atrial fibrillation occurred in 2 patients. Both episodes were connected with hypopotas- saemic values in the serum. Both patients died without returning to sinus rhythm.

Electrocardiograms were registered before and after lumbar puncture in 13 cases (Table 2). The mean pulse rate was $76.8 / \mathrm{min}$ before and $78.4 / \mathrm{min}$ after lumbar puncture. The difference is not significant $(P>0.7)$. 
The mean pulse rate in 13 patients was $79.7 / \mathrm{min}$ at admission and $78.9 / \mathrm{min}$ on the 6th day. This change also was not significant ( $\mathrm{P}>0.9)$.

The electrocardiograms returned to normal in 8 patients. These patients are included in the 12 patients who survived the disease (Table I). All patients who were unconscious at admission also had electrocardiographic abnormalities (Table I).

Blood pressure findings The mean blood pressure in 6 patients who had earlier had hypertensive values was $206 / 109 \mathrm{mmHg}$ at admission. The abnormalities in these patients can be seen in Table 1 . In 7 patients who were unconscious on admission the mean pressure at that time was $190 / 97 \mathrm{mmHg}$. The blood - pressure of 12 patients was measured at admission and on the third hospital morning. The mean systolic values were 166 and 148 $\mathrm{mmHg}$ and the mean diastolic values 93 and 9I, respectively. The fall in systolic pressure was significant $(0.025<\mathrm{P}<0.050)$, while that in diastolic pressure was not $(P>0.50)$. In no - patient did the normal blood pressure level at admission rise to a hypertensive value during the hospital stay.

Biochemical findings Catecholamine excretion was determined at least once in 18 patients. In II patients more than three - measurements were done (Fig. I). The

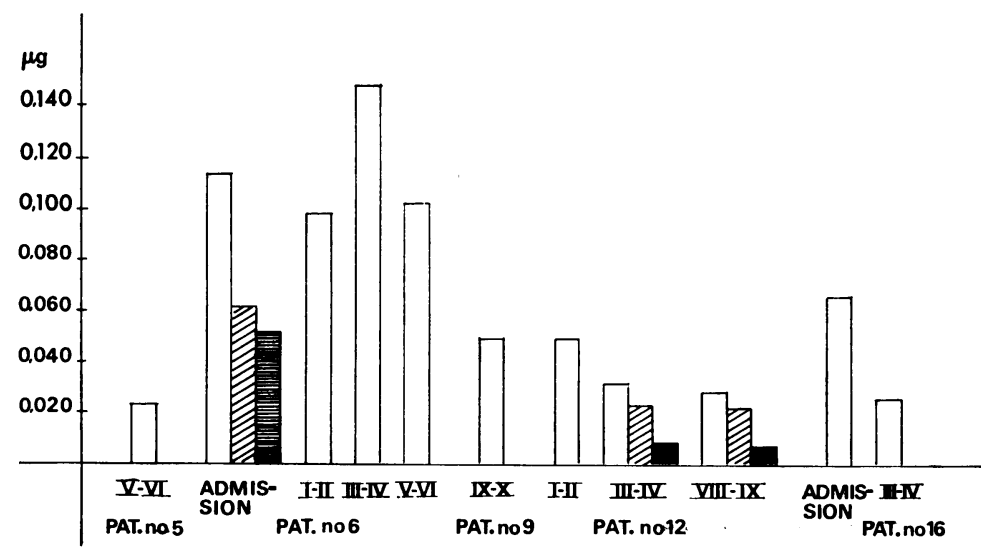

FIG. Ib The total urinary excretion of catecholamines, noradrenaline, and adrenaline in patients with subarachnoid haemorrhage and earlier known arterial hypertension. For symbols see Fig. Ia.

highest values were seen in a patient (Case 20) who was unconscious for the whole of the first 2 weeks.

In 29 determinations of urinary excretion of catecholamines, the adrenaline and noradrenaline contents were determined separately. In normal situations adrenaline should not exceed 25 per cent of the total catecholamine excretion. An increased excretion of

TABLE 2 The effect of lumbar puncture on the ECG pattern and pulse rate in patients with subarachnoid haemorrhage on admission to hospital

\begin{tabular}{|c|c|c|c|c|c|}
\hline \multirow{2}{*}{$\begin{array}{l}\text { Patient } \\
\text { No. }\end{array}$} & \multirow{2}{*}{$\begin{array}{l}\text { Time interval } \\
\text { between ECGs } \\
\text { (min) }\end{array}$} & \multicolumn{2}{|l|}{ Before lumbar puncture } & \multicolumn{2}{|l|}{ After lumbar puncture } \\
\hline & & $E C G$ & $\begin{array}{l}\text { Pulse rate } \\
\text { (min) }\end{array}$ & ECG abnormality & $\begin{array}{l}\text { Pulse rate } \\
\text { (min) }\end{array}$ \\
\hline $\mathbf{I}$ & 80 & U wave & 70 & None & 70 \\
\hline 3 & 80 & Normal & 86 & None & 74 \\
\hline $5^{\star}$ & 155 & U wave & 90 & $\mathrm{~T}$ flattening & 70 \\
\hline $6 *$ & 120 & Neg. U wave, $T$ neg., $P Q 0.22 \mathrm{sec}$ & 54 & PQ $0.17 \mathrm{sec}$ & 65 \\
\hline 8 & 210 & ST elevation & 61 & U wave & 67 \\
\hline II & 30 & QT prol. $(20 \%)$ & 75 & None & 84 \\
\hline $12^{\star}$ & 125 & Normal & 78 & None & 75 \\
\hline $13 t$ & 105 & Normal & 57 & ST-depression & 97 \\
\hline 14 & 25 & Normal & I32 & None & 121 \\
\hline $16^{\star}$ & 20 & $\begin{array}{l}\text { U wave, QT prol. (20\%), SVI + RV5 } \\
45 \mathrm{~mm}\end{array}$ & 74 & SVI + RV $537 \mathrm{~mm}$ & 83 \\
\hline $18+$ & 30 & $\begin{array}{l}\text { U wave, ST depr. and elev., T neg., } \\
\text { QT prol. }(20 \%), \text { SVI }+ \text { RV } 5 \\
41 \mathrm{~mm}\end{array}$ & 61 & $\begin{array}{l}\text { Ventricular extra- } \\
\text { systoles }\end{array}$ & 68 \\
\hline r9t & I IO & ST depr., QT prol. (20\%) & 100 & No ST depr. & 80 \\
\hline $20 t$ & 70 & $\begin{array}{l}\text { U wave, ST depr. P wave large, } \\
\text { SVI }+R_{5} 29 \mathrm{~mm}\end{array}$ & 60 & $\begin{array}{l}\text { No ST depr., ST } \\
\text { elevation, } \\
\text { SVI + RV5 } 35 \mathrm{~mm}\end{array}$ & 65 \\
\hline
\end{tabular}

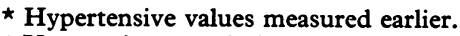

† Unconscious at admission. 
adrenaline was seen in II patients. This was the case in all 4 patients on whom these determinations were done on admission (Cases 6, 8, 13, and 19). In 2 other patients whose first determinations were done on the first hospital day the excretion of adrenaline exceeded 25 per cent of the total urinary output of catecholamines (Cases I and 20). In only one patient did excretion of adrenaline exceed 50 per cent of the total output. The urine was sampled for $3 \frac{1}{2}$ hours before his death (Case 13).

Transient ventricular extrasystoles were seen in one patient (Case 2) on the same day that his output of adrenaline reached 43 per cent of the total output of catecholamines, while the total output was normal. Sinus tachycardia in 5 patients was associated in 3 cases with an increased catecholamine output; in the other 2 this was not so. Of 7 patients with sinus bradycardia, 2 had increased catecholamine excretion values. Both events were seen on admission (Cases 6 and 13). In both of these patients the output of adrenaline was increased, being 46 per cent and 54 per cent of total output, respectively. Two other patients (Cases I and 8) had sinus bradycardia with normal total outputs but increased adrenaline outputs, these being, respectively, 29 per cent and 27 per cent of the totals.

Urinary output of metanephrines was determined at least 3 times in 9 patients. Clearly abnormal values were seen in only I patient (Case 20) who was unconscious for the first 2 weeks.

Serum lactic acid was determined in 13 patients. Abnormal values were seen only in 4 (Cases 3, 4, 19, and 20) and ranged from $22 \cdot 7$ to $28.3 \mathrm{mg} / 100 \mathrm{ml}$ (normal range $6-16 \mathrm{mg} / 100$ $\mathrm{ml}$ ). Two patients were unconscious on admission and had concomitant high lactic acid values. In these 2 patients (Cases 19 and Io) the values were normal on the 3 rd and 6th days, respectively. In 2 others the abnormal values were seen on the first day in one and on the fifth day in the other, and they returned to normal within 4 days. In all these patients with high lactic acid values, the blood gas and $p \mathrm{H}$ values were normal. No uniform correlation between electrocardiographic abnormalities and lactic acid values could be found.

Blood sugar was over $100 \mathrm{mg} / \mathrm{r} 00 \mathrm{ml}$ at admission or on the first hospital morning in Io patients out of 16 . These high values ranged from 107 to $184 \mathrm{mg} / 100 \mathrm{ml}$. On the sixth hospital day the blood glucose of 3 patients increased further over that at admission. Two additional patients with a normal value at admission had a raised value on the sixth day. Two weeks after admission only one of these patients had an increased blood sugar level, which persisted up to his death on the twentyfifth hospital day. In one patient (Case 3) high blood sugar values developed at hospital 2 weeks after admission; his diabetes mellitus needed further treatment with oral antidiabetics. The simultaneous plasma corticosteroid values, determined in 8 of the ro patients with a raised blood sugar level at admission or on the first day, were also increased in all cases (Fig. 2).

Plasma corticosteroids were determined in 17 patients. They were increased at admission or on the first day in 9 patients, ranging from 38.0 to $72.0 \mu \mathrm{g} / \mathrm{r} 00 \mathrm{ml}$ (upper limit of normal is $31 \mu \mathrm{g} / 100 \mathrm{ml}$ ). In only one patient (Case 3) did the initially normal value later become abnormal; this occurred on the 7 th day. In one patient (Case 7) the initially increased value rose further, being highest on the second hospital morning. In all other cases the increased value returned to normal within the following 4 days. No uniform correlations with concomitant electrocardiograms were found. The relation between simultaneous mean blood sugar, plasma corticosteroid, and urinary catecholamine output values is shown in Fig. 2.

Serum cholesterol, triglycerides, and NEFA: at admission the serum cholesterol was determined in 15 patients, the mean being $287 \mathrm{mg} /$ I00 $\mathrm{ml}$ (range from $173 \mathrm{mg}$ to $400 \mathrm{mg} / 100 \mathrm{ml}$ ).

Serum triglyceride values were within normal limits in 12 patients at admission (mean I.22 $\mathrm{mM} / \mathrm{l}$ ). At admission 7 patients (range $\mathrm{I} \cdot 05-2 \cdot 8 \mathrm{I} \mathrm{mEq} / \mathrm{l}$.) out of $\mathrm{I} 4$ had NEFA values over normal range. Abnormal NEFA values returned to normal within 4 days. The high NEFA values did not correlate in any way with the electrocardiographic abnormalities nor was there any correlation with changes in the urinary excretion of catecholamines.

Serum enzymes (CPK, GOT, GPT, LDH): these determinations were done on 16 patients. The abnormal values and their follow-up are presented in Table 3.

The case histories of the patients with raised CPK values revealed the following. One patient (No. I) was sawing wood when the acute attack overtook him, one (No. 3) had suddenly fallen down in the street, another (No. 4) had been doing light physical work for 4 hours, half-an-hour before the acute phase, one (No. 
TABLE 3 Serum enzyme (CPK, GOT, GPT, LDH) values in patients with subarachnoid haemorrhage who had abnormal findings: Normal limits: $C P K<0.72 I U, G O T<20 I U$, $G P T<I 9 I U$, and $L D H<I 80 I U$

\begin{tabular}{|c|c|c|c|c|c|c|c|c|c|c|c|c|c|}
\hline \multirow[t]{2}{*}{ Enzyme } & \multirow{2}{*}{$\begin{array}{l}\text { Patient } \\
\text { No. }\end{array}$} & \multicolumn{12}{|c|}{ Values on subsequent days } \\
\hline & & $A$ & $I$ & $I I$ & $I I I$ & IV & $V$ & $V I$ & $V I I$ & $V I I I$ & $I X$ & $x$ & $X V I I$ \\
\hline \multirow[t]{7}{*}{ CPK } & $\begin{array}{l}1 \\
3\end{array}$ & $r \cdot 62$ & I $\cdot 40$ & $1 \cdot 34$ & & 0.50 & $I \cdot 12$ & $69^{\star}$ & $\mathrm{I} \cdot 29$ & & 0.06 & $40^{\star}$ & $\begin{array}{c}10^{\star} \\
0.62\end{array}$ \\
\hline & $4^{\star}$ & & 115 & & & & & & & & 14 & & 17 \\
\hline & 8 & & & & 0 & 0.34 & & 0 & & & & 0.88 & \\
\hline & II & & 0.78 & & & & 0.78 & & & & O.II & & 0.34 \\
\hline & 19 & & 0.11 & & $7 \cdot 39$ & & & & & & & & \\
\hline & 20 & & & & 2.18 & & & & & & & & \\
\hline & 14 & I.OI & & & & & & & & & & & \\
\hline \multirow[t]{7}{*}{ GOT } & 3 & & 30 & & & & 27 & & 90 & & 180 & & 37 \\
\hline & 4 & & 12 & & 20 & & 49 & & & & 18 & & 10 \\
\hline & 7 & 13 & & 28 & & I3 & & Io & & & & I4 & I3 \\
\hline & Io & & 14 & & 23 & & 15 & I0 & & & & & \\
\hline & 19 & & 38 & & 65 & & & & & & & & \\
\hline & 20 & & 17 & & 19 & & 29 & & & & & 15 & 13 \\
\hline & 14 & 23 & & & & & & & & & & & \\
\hline \multirow[t]{5}{*}{ GPT } & 3 & & 22 & & & & 30 & & 125 & & 280 & & 100 \\
\hline & 4 & & I7 & & 38 & & 28 & & & & 87 & & 16 \\
\hline & 19 & & 35 & & 48 & & & & & & & & \\
\hline & 20 & & 13 & & 12 & & 15 & & & & & 23 & 15 \\
\hline & 14 & 25 & & & & & & & & & & & \\
\hline \multirow[t]{7}{*}{ LDH } & 3 & & 170 & & & & IIO & & 180 & & 305 & & 130 \\
\hline & 5 & & & & 170 & & & & & & 170 & & 255 \\
\hline & 7 & 250 & & 270 & & 160 & & 150 & & & & 140 & 140 \\
\hline & 9 & & & & 300 & & & & & & & 250 & 240 \\
\hline & 19 & & 280 & & 315 & & & & & & & & \\
\hline & 20 & & 205 & & 280 & & 150 & & & & & 220 & 220 \\
\hline & I4 & 203 & & & & & & & & & & & \\
\hline
\end{tabular}

* Normal limit for this CPK determination method is $<50 \mathrm{mU} / \mathrm{ml}$.

II) was sewing when the acute attack occurred, another (No. I4) had been taking alcohol for two preceding days and had fallen down in the street. The patient (No. 19) with the highest CPK value had fallen down at home, was unconscious, and died on the sixth day after admission. Another patient (No. 20) also was unconscious on admission: during transport to hospital he had been very restless, when the sample was taken on the third hospital day he was in the respirator.

In 2 patients (No. 3 and 4), the rise in SGOT and SGPT values was associated with $T$ wave flattening and subsequent slight $T$ wave inversion. The highest values in patient No. 3 were seen on the ninth hospital day (SGOT I80 IU, SGPT 280 IU). Carotid angiographies were done on the sixth and seventh days. In the other patient (No. 4) the enzyme levels concomitant with $\mathrm{T}$ wave inversion were SGOT $49 \mathrm{IU}$ and SGPT 28 IU.

$\bullet$

Serum potassium was determined on admission in 20 patients. Three of them had hypopotassaemia (No. 3, 15, 18), the values ranging from $3.2 \mathrm{mM} / 1$. to $3.5 \mathrm{mM} / \mathrm{l}$. Two of these patients died 6 and 28 hours after admission. The patient with the lowest potassium value (3.2 $\mathrm{mM})$ on admission also had atrial fibrillation. Another patient developed atrial fibrillation on the same day her serum potassium was $3.3 \mathrm{mM}$. Both of these patients with atrial fibrillation died without a return to sinus rhythm. Seven other patients developed hypopotassaemia during their hospital stay (patients 5, 6, 10, 14, 16, 19, 20). Their lowest values ranged from 2.7 to $3.5 \mathrm{mM}$. In 4 of these 7 patients the values were lowest on the second morning in hospital and in 2 patients on the third and fourth morning. In patient No. I9 the very low value of $2.7 \mathrm{mM}$ was seen on the fifth day, preceding his death on the next day. The most common electrocardiographic abnormality concomitant with the lowest potassium values was an abnormal $U$ wave ( 5 cases). There was a large $P$ wave in 3 cases, and also ST depression. A negative $T$ wave was seen in 2 cases. QT (QaT) interval prolongation occurred with the lowest potassium values in 5 cases. In these cases QT 


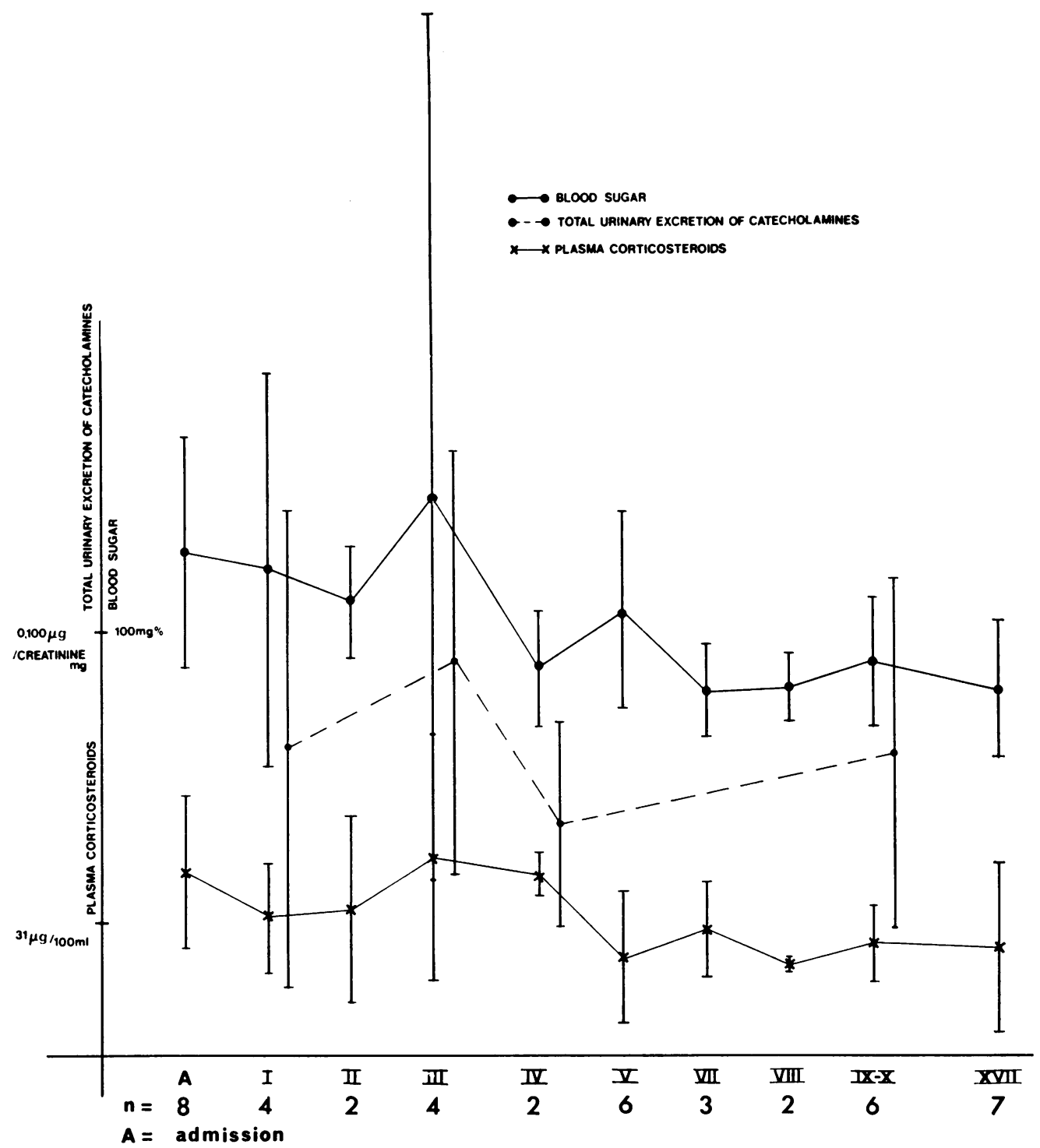

FIG. 2 The mean daily values with I SD of blood sugar (upper line), total urinary output of catecholamines (middle line), and plasma corticosteroids (lower line) in patients with subarachnoid haemorrhage. I, II, III etc. stand for hospital days after admission.

prolongation was connected with a $\mathrm{U}$ wave abnormality in 2 cases only.

Necropsy findings Necropsy was performed on 6 of the 8 patients who died. In all except one the heart weight was normal, the range being $350-460 \mathrm{~g}$. Patient No. 18, who had shown the most prominent electrocardiographic abnormalities (Table 1 ), had also the largest heart $(740 \mathrm{~g})$ in the necropsied cases. His heart muscle was discoloured, but microscopy revealed no changes to support a recent myocardial infarction. His mitral papillary muscles were fibrotic. Necropsy revealed slight coronary atherosclerosis without stenosis in 3 patients, and neither signs of recent transmural subendocardial affections nor evidence of acute left ventricular failure were seen.

Site of haemorrhage The subarachnoid haemorrhage was verified in all the necropsies. Carotid angiography was done on 7 other patients; in 2 cases no aneurysm could be 
found. Thus the site of aneurysm could be located in II cases. It was in the anterior cranial fossa in 7 cases (patients $3,6,8,14,15$, 17 , and 20), in the middle fossa in 2 (patients 13 and 17), and in the posterior fossa in 2 (patients 18 and 19).

\section{Discussion}

There have been many attempts to explain the genesis of electrocardiographic abnormalities in subarachnoid haemorrhage. They have been attributed to hypopotassaemia (Haan, 1963; Hersch, 1964), to concomitant subendocardial haemorrhage (Koskelo et al., 1964), to alterations in the function of the autonomous nervous system (Burch, Meyers, and Abildskov, 1954), to focal myocytolysis

$\checkmark$ in the myocardium (Connor, 1968), and to interference in cerebral region 13 (Cropp and Manning, 1960).

The incidence of electrocardiographic abnormalities in the presence of subarachnoid haemorrhage has also varied widely; and this is also the case with the different types of - abnormality in the electrocardiogram. This variability may be due to multipotent factors encountered in subarachnoid haemorrhage. Not only the current factors but also the previous condition of the patient may influence the electrocardiogram. The previous cardiovascular state bearing in mind the age of the - patient may be remarkable potential factors.

In the present study an abnormal $U$ wave was the most commonly seen change in the electrocardiogram (in $65 \%$ ). The changes next in frequency were prolongation of the QT interval (55\%), ST depression (50\%), T wave flattening or inversion $(45 \%), \mathrm{SVI}+$ $\mathrm{RV}_{5}=35 \mathrm{~mm}(\mathbf{4 0} \%)$. A prominent $\mathrm{P}$ wave in lead II was seen in 35 per cent of the patients but only in 2 cases concomitantly with $S V_{I}+R V_{5} \geqq 35 \mathrm{~mm}$. Sinus bradycardia was more frequent (in $35 \%$ ) than sinus tachycardia (in $25 \%$ ). The 100 per cent rate of occurrence of electrocardiographic in our series might find its explanation in the frequent follow-up of electrocardiograms. The previous arterial hypertension did not seem to accentuate the electrocardiographic abnormalities. The role of electrolyte disturbances, especially hypopotassaemia, has been mentioned as a causative factor in these abnormalities in subarachnoid haemorrhage (Hersch, I964), but contradictory conclusions have also been presented (Hunt et al., I969; Shuster, 1960).

- The prominent $P$ wave, QT prolongation, ST depression, $T$ wave flattening, and $T$ wave inversion are referred to hypopotassaemia. All these changes were seen in our patients,
Io of whom had hypopotassaemia (serum potassium $<3.6 \mathrm{mM} / \mathrm{l}$.). The same was the case with an abnormal $U$ wave, not always connected with low potassium values on the same day, but most often seen in patients who had hypopotassaemia some days earlier or later. The relation between the potassium ion and the electrocardiogram pattern is not so simple. Serum potassium values do not necessarily reflect the myocardial ionic concentrations. The causative role of the measured low serum potassium in the generation of atrial fibrillation in two of our patients can be questioned. The importance of this finding is however augmented by the fact that both patients died within 30 hours of the appearance of this abnormal rhythm. The possible role of the serum potassium ion in the genesis of the $\mathrm{U}$ wave is not yet clear and many other factors seem to be responsible too (Lepeschkin, 1969). The rise in serum enzyme activities with concomitant changes in the electrocardiogram have been reported to raise difficulties in differential diagnosis in connexion with cerebrovascular accidents. In this study abnormal serum CPK values were most often seen during the first 3 days in hospital (Table 3 ). All the other serum enzyme rises were more scattered over the follow-up time (Table 3). In only 2 patients were the high SGOT and SGPT values associated with slight $T$ wave inversion. No other symptoms or signs of myocardial infarction were seen in these patients. However, the possibility of a minute silent subendocardial infarction could not be excluded. In many patients the increases in serum enzyme levels seemed to be caused by extracardial factors, such as muscle injury, physical work, misuse of alcohol, etc.

It is obvious that subarachnoid haemorrhage induces both psychic and physical stress. Consequently the abnormalities on the cardiogram have been attributed to the autonomous nervous system. Both sympathetic and vagal overactivity separately (Cropp and Manning, 1960; Daoud and Surawicz, 1970; Burch, Colcolough, and Giles, 1970) and together (Visscher, Haddy, and Stephens, I956) have been presented as causative factors.

In the present study the urinary output of catecholamines was not increased in all cases at admission. The highest values were scattered quite widely over the follow-up time. The role of different kinds of stress on the excretion of metanephrines was evident in some cases (carotid angiographies, lumbar punctures, etc.). The rises in the outputs of catecholamines could not uniformly be related to changes in the electrocardiogram.

The increased release of corticosteroids has 
also been attributed to psychic or physical stress. In 9 patients out of 17 the plasma corticosteroids were raised. The values always returned to normal within 4 days. In 8 patients out of 10 the plasma corticosteroids were raised simultaneously with the blood sugar values at admission. In only one of these patients did an overt diabetes mellitus develop.

It may be concluded that no close relation exists between electrocardiographic abnormalities and any single laboratory test. However, this does not exclude the potential importance of some single agent. The significance of functional factors may be greatly variable in subarachnoid haemorrhage. The influence of a single functional agent on the target organ, i.e. the myocardium, may vary considerably from moment to moment. The influence of a single factor is determined not only by its quantity; thus the response of the target organ to a factor, and further the relation between different functional factors, may be changed by subarachnoid haemorrhage. Therefore, it may be assumed that electrocardiographic abnormalities of various quantity or quality may be seen in conditions in which serum concentration of even a strong agent is not necessarily increased.

\section{References}

Burch, G. E., Colcolough, H., and Giles, T. (1970). Intracranial lesions and the heart. American Heart fournal, 80, 574 .

Burch, G. E., DePasquale, N., and Malaret, G. (1960). Selected problems in electrocardiography. Annals of Internal Medicine, 52, 587.

Burch, G. E., Meyers, R., and Abildskov, J. A. (1954). A new electrocardiographic pattern observed in cerebrovascular accidents. Circulation, 9, 719.

Byer, E., Ashman, R., and Toth, L. A. (1947). Electrocardiograms with large upright $T$ waves and long Q-T intervals. American Heart fournal, 33, 796.

Connor, R. C. R. (1968). Heart damage associated with intracranial lesions. British Medical fournal, 3, 29.

Cropp, G. J., and Manning, G. W. (I960). Electrocardiographic changes simulating myocardial ischemia and infarction associated with spontaneous intracranial haemorrhage. Circulation, 22, 25.

Daoud, F. S., and Surawicz, B. (1970). The effect of isoproterenol (ISP) on the electrocardiogram in patients with intracranial lesions. American fournal of Cardiology, 26, 629.

Haan, D. (1963). Elektrokardiogramm- und Elektrolytveränderungen bei zerebralen Massenblutungen. Münchener medizinische Wochenschrift, 105, 881.

Hersch, C. (1964). Electrocardiographic changes in subarachnoid haemorrhage, meningitis, and intracranial space-occupying lesions. British Heart fournal, 26, 785 .

Hoff brand, B. I., and Morgan, B. D. G. (1965). Functional significance of electrocardiographic changes associated with subarachnoid haemorrhage. Lancet, $1,844$.

Hunt, D., McRae, C., and Zapf, P. (1969). Electrocardiographic and serum enzyme changes in subarachnoid haemorrhage. American Heart fournal, 77, 479.

Ilinskii, B. V., and Astrakhantseva, S. P. (1967). Character and genesis of electrocardiographic changes in cerebral insults. Cor et Vasa, 9, 26I.

Koskelo, P., Punsar, S., and Sipilä, W. (1964). Subendocardial hemorrhage and e.c.g. changes in intracranial bleeding. British Medical fournal, I, 1479.

Kreus, K.-E., Kemilä, S. J., and Takala, J. K. (1969). Electrocardiographic changes in cerebrovascular accidents. Acta Medica Scandinavica, 185, 327.

Lepeschkin, E. (1955). The $U$ wave of the electrocardiogram. Archives of Internal Medicine, 96, 600.

Lepeschkin, E. (1969). The U wave of the electrocardiogram. Modern Concepts of Cardiovascular Disease, 38, 39.

Lipman, B. S., and Massie, E. (1965). Clinical Scalar Electrocardiography, 5th ed. Year Book Medical Publishers, Chicago.

Shuster, S. (1960). The electrocardiogram in subarachnoid haemorrhage. British Heart fournal, 22, 316.

Srivastava, S. C., and Robson, A. O. (1964). Electrocardiographic abnormalities associated with subarachnoid haemorrhage. Lancet, 2, $43 \mathrm{I}$.

Visscher, M. B., Haddy, F. J., and Stephens, G. (1956). The physiology and pharmacology of lung edema. Pharmacological Reviews, 8, 389.

Wong, T. C., and Cooper, E. S. (1969). Atrial fibrillation with ventricular slowing in a patient with spontaneous subarachnoid hemorrhage. American fournal of Cardiology, 23, 473.

Requests for reprints to Dr. A. Eisalo, First Department of Medicine, Helsinki University Central Hospital, Helsinki 29, Finland. 